\title{
تقنيين مقياس ميداس للذكاءات المتعددة لطلاب الصف الحادي عشر في محافظة شمالي الباطنة بسلطنة عمان
}

\author{
Standardization of MIDAS with Grade Eleven Omani Students in the
}

Governate of North Albatinah

\author{
Abdul Aziz Abdullah Mohammed \\ ALmazruii \\ Ministry of Higher Education, \\ Sultanate of Oman, \\ Muscat, Oman \\ abdulaziz2.aa91@gmail.com \\ Ali Mohammed Ibrahim \\ Kulliyyah of Education, \\ International Islamic University Malaysia, \\ Kuala Lumpur, Malaysia

\section{Rashid Saif Almehrizi} \\ College of Education, \\ Sultan Qaboos University, \\ Sultanate of Oman, Muscat, Oman \\ Abdul Qawi Salem Alzubaidi \\ College of Education, \\ Sultan Qaboos University, \\ Sultanate of Oman, Muscat, Oman
}




\title{
مُلنَّص البحث
}

سعى هذا البحث إلى تقنين مقياس ميداس MIDAS للذكاءات المتعددة للمراهقين من تأليف برانتون

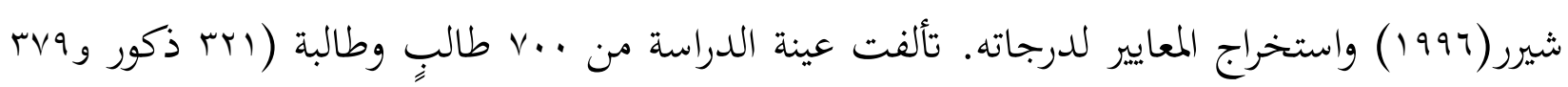
إناث) من طلبة الصف الحادي عشر بمحافظة شمال الباطنة في سلطنة عمان. واستخدم مع البحث كلا

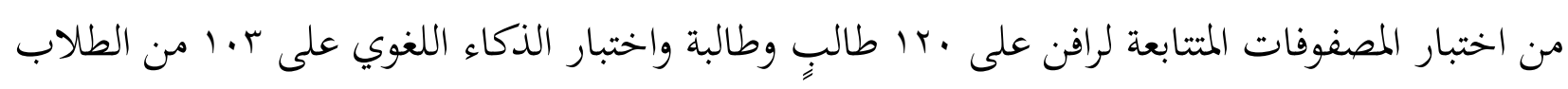
وذلك لحساب الصدق التلازمي للمقياس. تم تحليل البيانات باستخدام برنامج SPSS، وبرنامج الليزرال LISREL8.14. وقد أشارت النتائج إلى تمتع المقياس بالصدق البنائي، والصدق التلازمي مع اختبار رافن، ومع اختبار الذكاء اللغوي. وأشارت نتائج التحليل العاملي التوكيدي أن مقياس ميداس حقق مؤشرات حسن المطابقة المقبولة. وأظهر المقياس معاملات ثبات عالية بطريقة ألفاكرونباخ، وطريقة إعادة التطبيق. كما تم حساب الرتب المئينية وذلك لإشتقاق معايير للدرجات الخام. وفي ضوء نتائج البحث يمكن استخدام مقياس ميداس في التوجيه المهني، والإستفادة من معايير الدراسة في التعرف على مستوى الذكاءات المتعددة لدى كل طالب، والعمل على تنمية هذه الذكاءات من خلال استخدام أساليب وأنشطة تدريس مناسبة.. الكلمات المفتاحية: مقياس ميداس للذكاءات المتعددة، الخصائص السيكومترية، المعايير، سلطنة عمان

\begin{abstract}
The purpose of this study was to examine the psychometric properties of Shearer's (1996) Multiple Intelligence Developmental Assessment Scale (MIDAS) used with a sample of Grade 11 Omani students. The sample consisted of 700 Grade 11 students ( 321 males and 379 females) from the Governorate of North Albatinah in the Sultanate of Oman. The study also administered the Raven progressive matrices test and the verbal intelligence test to two different samples of 120 and 103 students, respectively, for concurrent validity. The data analysis was conducted using SPSS and LISREL8.14. The results showed that MIDAS has acceptable construct and concurrent validity for both tests. Also, the results of a confirmatory factor analysis (CFA) showed acceptable goodness of fit indices for MIDAS. Similarly, both the internal consistency and test-retest reliability of the scale showed satisfactory results. Finally, the percentile ranks for MIDAS scores were computed as norm scores for the scale. In conclusion, the study confirms the possibility of using the MIDAS test for career guidance purposes. It also provides indicators to identify the multiple intelligence levels of students with the aim of enhancing their intellectual capability using appropriate instructional methods and activities.
\end{abstract}

Keywords: MIDAS for teens, MIDAS for career guidance, intelligence level assessment, psychometric properties, Grade 11 Omani students 


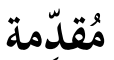

منذ أن عرض (Gardner، ras1) نظرية الذكاءات المتعددة، واستخدمها لقياس الذكاء بدلاً من المفاهيم التقليدية أو مفهوم الذكاء العام الذي قدمه Spearman؛ حرص التربويون في بيئات كثيرة على الاستفادة من هذه النظرية وتطبيقاتا، فقاسوا الذكاءات المتعددة من المراحل الدراسية الأولى إلى المراحل الجامعية؛ لأن ذلك يساعد في التحديد المبكر للذكاءات التي يتميز بها الطفل، ومن ثم؛ صقل هذه الذكاءات وتوجيه الطفل نحو ميوله المهنية (Shearer، 199>). وقد كثرت الدراسات المرتبطة بمبحث الذكاءات المتعددة وحاولت تحديد علاقته بعدد من المتغيرات في البيئة التربوية من مثل: المرحلة الدراسية، والنوع، والتخصص، والدافعية، والتحصيل الدراسي، وغيرها، فإعداد الطالب وفق ميوله المهنية يساعده على النجاح خارج المدرسة، وفي حياته العملية؛ إذ إن تطبيقات هذه النظرية داخل المدرسة تساعد في إعداد الطالب، وصقل المهارات والقدرات التي يحتاجها المجتمع. وقد قسم جاردنر الذكاءات إلى ثمانية أنواع يسهم كل منها في صقل مهارة مختلفة لدى الطالب (قوشحة، r..r)، وتشمل هذه الذكاءات: اللفظي اللغوي، والمنطقي الرياضي، والمكاني، والجسمي الحركي، والموسيقي الإيقاعي، والاجتماعي، والذاتي، والطبيعي (Gardner، 999 (1)، وبينت بعض الدراسات أن إدراك المعلمين تطبيقات هذه النظرية ومعرفة هذه الذكاءات يساعدهم في تنميتها لدى تلاميذهم، وإعداد المناهج، واختيار طرق التدريس المناسبة، ومراعاة قدرات الطلبة الفردية، ومواكبة التقدم العلمي والتطور التقاني (عفانة

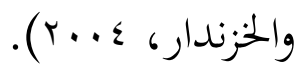

كما أن الكشف المبكر عن ذكاءات الطلبة قد يسهم في علاج مشكلة انخفاض المستوى التحصيلي

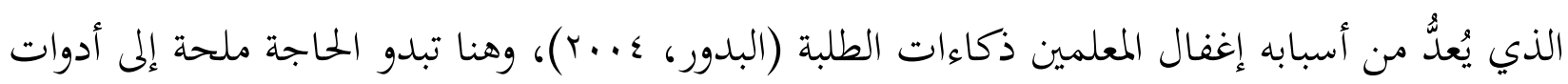
مقننة على البيئة العمانية؛ يمكن من خلالها تحديد نقاط القوة والضعف لدى كل طالب، والذكاءات التي يتميز بها؛ لتوجيهـم جميعًا نحو اختيار المواد والتخصصات التي تناسب هذه الذكاءات. Multiple ومن بين أدوات قياس الذكاءات المتعددة يبرز مقياس التقويم النمائي للذكاءات المتعددة ونئ Assessment Scales MIDAS المقاييس الحديثة عالية الجودة التي صُممت وفق معايير الجودة العالمية للاختبارات، وبالاستفادة من الإطار 
النظري لنظرية جاردنر الذي أوصى باستخدام هذا المقياس في الكشف عن الذكاءات المتعددة لدى الطلبة، وهو مقياس وصفي ذاتي التقدير (Shearer، 997 ([أ]).

\section{مشكلة البحث}

يعمد الاتجاه التربوي الحديث إلى استخدام مقاييس للكشف المبكر عن ذكاءات الطلاب واستعداداتم منذ المرحلتين الابتدائية والإعدادية، ومن ثم؛ توجيههم في المرحلة الثانوية لاختيار المواد التي تناسب هذه

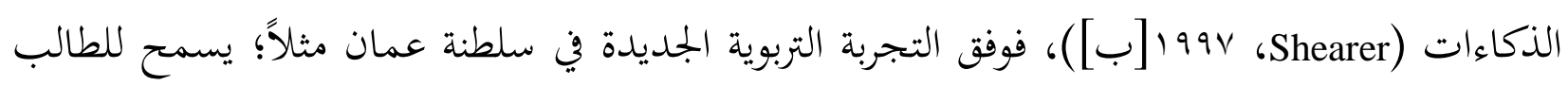
باختيار مواد دراسية وفق ميوله واستعداداته بالإضافة إلى المواد الإجبارية، كما أنشئ مركز خاص بالتوجيه

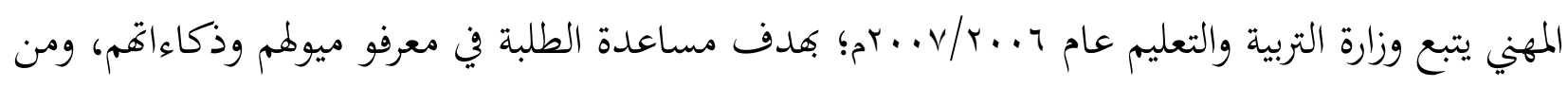
ثم؛ اختيار التخصصات والمهن التي تتفق مع هذه الميول والذكاءات (وزارة التربية والتعليم، ؟ +.ب)، وبما أن الميول وحدها لا تكفي لتوجيه الطالب إلى اختيار التخصص؛ قد يسهم استخدام مقياس ميداس للذكاءات المتعددة في الكشف عن ذكاءات الطلبة، ويسهل عملية توجيهمم إلى التخصصات التي تتناسب مع قدراهم واستعداداتم.

ولأن مقياس ميداس للذكاءات المتعددة يتميز بصدق وثبات مرتفعين وقوة تنبؤية عالية (Shearer، (†)؛ يُعدُّ من المقاييس التي تناسب هذا الغرض، ولأن الاختبارات التي تقيس الذكاءات المتعددة لما تُقنن بعد في سلطنة عمان؛ برزت فكرة تقنين مقياس التقويم النمائي للذكاءات المتعددة (MIDAS)، مما يساعد المعلمين في معرفة نقاط القوة والضعف لدى الطلبة، ومن ثم؛ تصميم النشاطات واختيار طرق التدريس التي تتفق مع ميولم وقدراتم، والعمل على تنمية هذه الذكاءات. وتصاغ مشكلة البحث في السؤال الرئيس الآتي:

ما الخصائص السيكومترية لمقياس ميداس لقياس الذكاءات المتعددة لدى طلبة الصف الحادي عشر في محافظة شمالي الباطنة بسلطنة عمان؟

أسئلة البحث

تتفرع عن مشكلة البحث الأسئلة الفرعية الآتية: 
ا. ـما مؤشرات صدق مقياس الذكاءات المتعددة على طلبة الصف الحادي عشر في محافظة شمالي

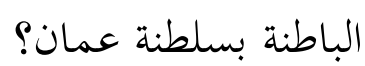

r. ما مؤشرات ثبات مقياس الذكاءات المتعددة على طلبة الصف الحادي عشر في محافظة شمالي

الباطنة بسلطنة عمان؟ - ان

r. ما الدرجات المعيارية لمقياس الذكاءات المتعددة على طلبة الصف الحادي عشر في محافظة شمالي

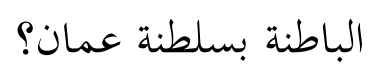

\section{أهداف البحث}

يتمثل الهدف الرئيس لهذا البحث في تقنين مقياس ميداس لقياس الذكاءات المتعددة في البيئة العمانية؛ من أجل إيجاد أداة تربوية يمكن أن توظف في معرفة الذكاءات المتعددة لدى طلبة الصف الحلادي عشر في في محافظة شثمالي الباطنة بسلطنة عمان، وتتفرع من هذا الهدف الرئيس الأهداف الفرعية الآتية: ا ـ التحقق من مؤشرات صدق مقياس ميداس لقياس الذكاءات المتعددة على طلبة الصف الحادي عشر في محافظة شمالي الباطنة بسلطنة عمان. r. التحقق من مؤشرات ثبات مقياس ميداس لقياس الذكاءات المتعددة على طلبة الصف الحادي عشر في محافظة شمالي الباطنة بسلطنة عمان. r. استخراج الدرجات المعيارية لمقياس الذكاءات المتعددة على طلبة الصف الحادي عشر في محافظة شمالي الباطنة بسلطنة عمان. ع ـ مساعدة الطلبة في معرفة ذكاءاقم المختلفة التي تؤهلهم لاختيار التخصص المناسب وتحديد المهنة

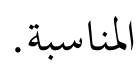

\section{أهمية البحث}

يستمد هذا البحث أهميته من ضرورة توفر أداة ذات خصائص سيكومترية جيدة تساعد المتخصصين المهنيين في وزارة التربية والتعليم لتوجيه الطلبة إلى التخصصات التي تتلاءم مع أساليب تعلمهم وذكاءاقم المتعددة، ووضع الطالب المناسب في التخصص المناسب. 


$$
\text { ومن المؤمل أن يسهم هذا البحث في الجوانب الآتية: }
$$

ا ـ توفير أداة تشخيصية تتحقق فيها الشروط السيكومترية من حيث الصدق والثبات، والمعايير التي

يمكن استخدامها في قياس الذكاءات المتعددة لدى الطلبة.

r . أول دراسة تجري في المجتمع العماني لتقنين واحد من مقاييس الذكاءات المتعددة.

r. وضع بعض المقترحات والحلول التي يمكن الاستفادة منها في التوجيه المهني وتطوير المناهج الدراسية؛ لعلاج الخفاض التحصيل الدراسي.

\section{حدود البحث ومصطلحاته}

اقتصر هذا البحث على عينة من طلبة الصف الحادي عشر في مدارس محافظة شمالي الباطنة ثاني أكبر محافظة في سلطنة عمان من حيث الكثافة السكانية إذ تبلغ نسبة السكان فيها (0,17\%) من إجمالي

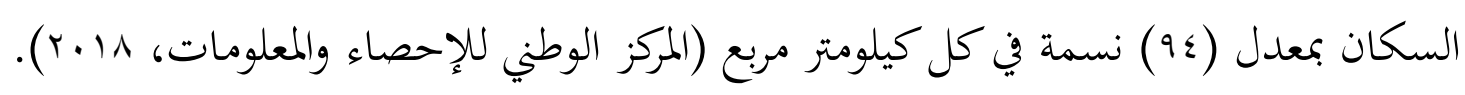
التقنين Standardization: أن يكون بناء نتائج الاختبار وتصحيحها وتفسيرها مستندًا إلى قواعد محددة، فتتوحد فيه وتحدد في دقة مواد الاختبار، وطريقة تطبيقه، وتعليمات إجابته، وطريقة تصحيحه، أو تسجيل درجاته، فهو ينطبق على الظروف المثالية التي يستطيع فيها مصمم أداة القياس ضبط جميع المتغيرات ما عدا المتغير الذي يهدف الاختبار قياسه (علام، ج...ب).

ويُقصد بالتقنين إجرائيًّا استخراج الخصائص السيكومترية لمفردات مقياس ميداس للمراهقين؛ بحساب لئساب الصدق والثبات والمعيار الميئيني بعد تطبيقه على عينة ممثلة لمجتمع البحث؛ من أجل سهولة استخدامه وصحة اعتماد نتائجه.

مقياس ميداس MIDAS: مقياس التقويم النمائي للذكاءات المتعددة Multiple Intelligences: Shearer) Development Assessment Scales هي: الموسيقي، والجسمي الحركي، والمنطقي الرياضي، والمكاني، واللفظي اللغوي، والاجتماعي، والذاتي، والطبيعي، ويتكون من (199) فقرة. 


\section{الإطار النظري}

قوبلت فكرة أن هناك ذكاء واحدًا يقيسه العامل العام (g) الذي أشار إليه سبيرمان Spearman، وأن الفرد يولد بإمكانية محددة من الذكاء؛ قوبلت باعتراض بعض علماء النفس منذ عشرينيات القرن الماضي، فالكفاءة المهنية التي بمتاز بها بعض الناس لا يمكن إرجاعها إلى الذكاء العام بالمعنى التقليدي للذكاء، كما لا يمكن لمقاييس الذكاء المعروفة تقييم تلك الكفاءة (Gardner، بوه 19). ويرى (Gardner، و99 1 ) أن هناك براهين مقنعة تثبت أن لدى الإنسان عدة كفاءات ذهنية مستقلة نسبيًّا، فقد قدم نظريتة الجديدة التي أطلق عليها اسم "الذكاءات المتعددة" Multiple Intelligences في كتابه "أطر العقل" Frames of Mind، وعرض فيه وجهة نظر جديدة تختلف عن النظرة التقليدية للذكاء، فهو يرى أن الذكاء ليس نوعًا واحدًا، وإنما هناك سبعة أنواع منفصلة من الذكاء هي: الموسيقي، والحركي الجسمي، والمنطقي الرياضي، والمكاني، واللغوي اللفظي، والاجتماعي، والذاتي (Gardner، بهرا)، ثم أضاف إليها ذكاء آخر هو الطبيعي (Gardner، 1999). ويرى (Gardner، זبه 1 ) أن الذكاء إمكانية نفسية حيوية Biopsychology Potenial لمعالجة المعلومات التي يمكن تنشيطها في بيئة ثقافية لحل المشكلات أو ابتكار المنتجات التي لها قيمة في ثقافة ما، ويرى أيضًا أن الأفراد يختلفون في الذكاءات المتعددة بسبب الوراثة والظروف البيئية (الخزندار، r...r)، وتؤكد (Helms، بو9 1 ) ما دعا إليه جاردنر في مفهومه عن الذكاء؛ أن العوامل الثقافية تمثل مجموعة ثالثة من المتغيرات المؤثرة في الذكاء جنبًا إلى جنب مع الوراثة والبيئة. وهناك أربعة أشكال عامة لتقويم مقياس ميداس تختلف باختلاف المراحل العمرية؛ هي: مقياس ميداس للبالغين الذين تتجاوز أعمارهم ·r عامًا، ويتكون من (1/9) فقرة على هيئة تقرير ذاتي. مقياس ميداس للمراهقين، وهو استبانة بسيطة لمن تتراوح أعمارهم ما بين ؛ (11) سنة، ويتكون من (199) فقرة على هيئة تقرير ذاتي. مقياس ميداس للأطفال (1) "كل شيء عني"، للأطفال أعمارهم ما بين 9- ــا سنة.

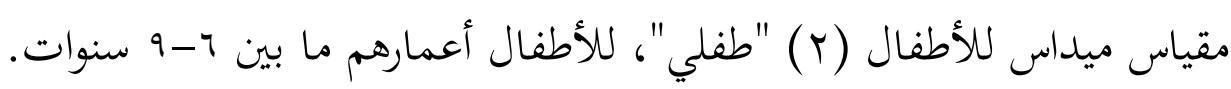

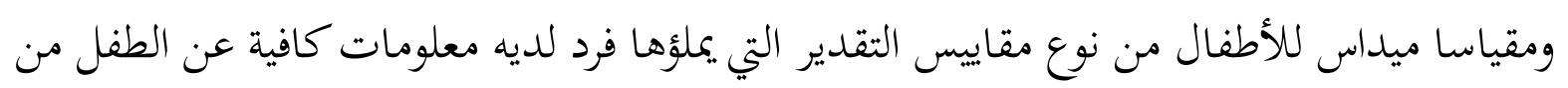
مثل ولي الأمر أو المعلم أو المختص النفسي. 


$$
\text { ويتكون مقياس ميداس للمراهقين من ثمانية ذكاءات (Shearer، } 1997 \text { ([أ])؛ هي: }
$$

ا ـ الذكاء الموسيقي: يتألف من (عا) فقرة تقيس: القدرة الصوتية، والمهارة على العزف بآلة موسيقية، والقدرة على التلحين، والتذوق الموسيقي. r. الذكاء الجسمي الحركي: يتألف من (rا) فقرة تقيس: النشاط الرياضي (التوازن والانسجام الحركي)، والبراعة الجسدية (التمثيل والجمباز). r. الذكاء المنطقي الرياضي: يتألف من (V) فقرة تقيس: العمليات الحسابية اليومية، وحل المشاكل اليومية، والألعاب التي تحتاج مهارة وإستراتيجية. ــ الذكاء المكاني: يتألف من (10) فقرة تقيس: التصميم الفني، والعمل بالأشياء التي تتطلب تنسيق حركة العين والأيدي (البناء والتنظيم والتزيين)، وإدراك الفضاء (حل المشاكل التي تتطلب إدراك الأشياء عبر الفضاء من مثل قيادة السيارة). ه. الذكاء اللفظي اللغوي: يتألف من (•r) فقرة تقيس: الحساسية التعبيرية (المهارة في استخدام الكلمات للأغراض التعبيرية)، والمهارة البلاغية (المهارة في استخدام اللغة في الإقناع والحوار مع الآخرين)، والقدرة على الكتابة في البمال الأكاديمي (كتابة البحوث والتقارير والقصص والرسائل)، والذاكرة اللفظية (القراءة والكتابة). 7 ـ الذكاء الاجتماعي: يتألف من (1) فقرة تقيس: الحساسية الاجتماعية (الإحساس وفهم سلوك الآخرين ومشاعرهم ونظراتم)، والإقناع الاجتماعي (القدرة على التأثير في الآخرين)، والعمل الاجتماعي (الاهتمام

$$
\text { والمهارة في المهن التي تحتاج إلى العمل مع الآخرين). }
$$

V. الذكاء الذاتي: يتألف من (9) فقرات تقيس: فاعلية المعرفة الشخصية (وعي نقاط القوة والحاجات لدى الفرد، والقدرة على التخطيط بكفاءة لتحقيق الأهداف الشخصية)، والقدرة على الانسجام مع الآخرين،

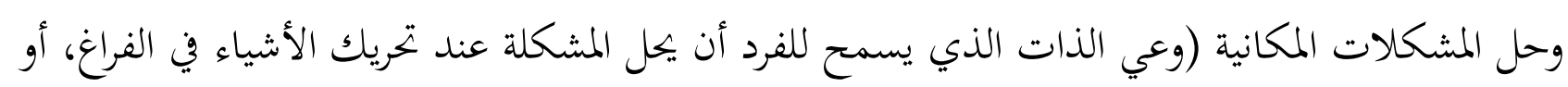
وعي المرء تخيلاته العقلية). 1. الذكاء الطبيعي: يتألف من (rاء) فقرة تقيس: العناية بالحيوان (فهم سلوك الحيوان واحتياجاته)، والعناية بالنباتات (فهم كيفية التعامل مع النباتات من مثل عمل الحدائق والمزارع)، والعلوم (معرفة طبيعة القوى الكامنة في الطقس والفيزياء وأنواع الاستفسارات العلمية). 


\section{الدراسات السابقة}

\section{أولاً: دراسات هدفت إلى تقنين مقياس ميداس}

أجرى (Shearer، 1994([أ]) أربع دراسات في ست سنوات في الولايات المتحدة الأمريكية، تراوح فيها

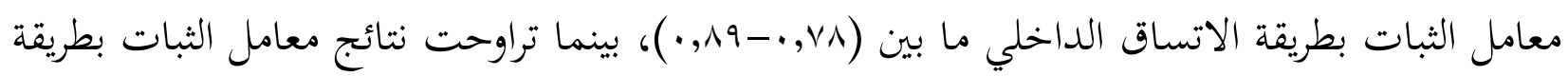

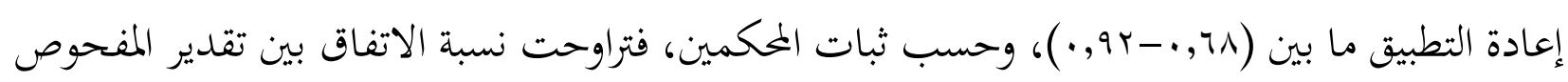
لذاته وتقدير المفحوصين اللذين اختارهما لتعبئة المقياس عن ذكاءاته ما بين (V0,..-10,.))، وللتحقق من صدق التكوين أجرى شيرر دراسة هدفت إلى التحقق من مدى قدرة مقياس ميداس على التمبيز بين سبعة مقاييس وُصفت في نظرية جاردنر للذكاءات المتعددة، واشتمل التحليل العاملي الاستكشافي على (وء؟ب) مفحوصًا، فأشارت النتائج إلى أن المقياس استطاع أن يميز بين سبعة مكونات عاملية، وأضاف عاملاً ثامنًا، وللتحقق من الصدق التبؤي للمقياس أجرى شيرر أيضًا دراسة هدفت إلى تعرُّف مدى الارتباط بين التقدير الذاتي للطلبة لذكاءاقم، وتقدير المحاضرين لذكاءات الطلبة، وأشارت النتائج إلى ارتفاع معاملات الارتباط بين مقياس التقدير الذاتي الذي أكمله الطالب والمقياس الذي أكمله المحاضر لوصف ذكاءات كل من طلبته، كما استخدم شيرر طريقة المجموعات المتقابلة بالاستفادة من نتائج الدراسات السابقة التي طبقها على مجموعة من طلبة جامعتين، فقارن بين نتائج المجموعات في كل ذكاء، وأظهرت النتائج مثلاً أن طلبة التصميم الداخلي حصلوا على درجات أعلى في الذكاء المكاني من طلبة الذكاء الموسيقي أو غيرهم، وحصل طلبة الرياضيات على درجات أعلى في الذكاء المنطقي الرياضي.

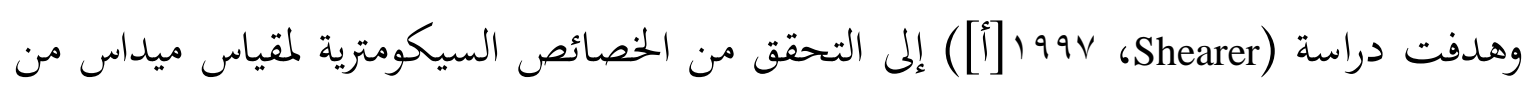
خلال فحص ارتباطه بمقياس الطلاقة اللفظية، ومقياس ويكسلر للأطفال (Wechsler)، ـ991)، وذلك مُك للتحقق من الصدق التلازمي لمقياس ميداس، فأشارت النتائج إلى أن أعلى ارتباط كان بين الذكاء اللغوي والطلاقة اللفظية، أما بالنسبة إلى أعلى ارتباط بين المقاييس الفرعية والمقياس الكلي فكان بين الذكاء المنطقي تم الذاتي مع المقياس الكلي للذكاءات المتعددة. وهدفت دراسة (طوخي، 17 +r) إلى تقنين مقياس ميداس لقياس الذكاءات المتعددة للمراهقين على البيئة السعودية، وتكونت عينة الدراسة من (·r) من طالبات المرحلة المتوسطة في مكة المكرمة، 
واستخدمت الدراسة مقياس ميداس الذي أعده برانتون شيرر، وأشارت نتائج الدراسة إلى تحقق صدق المتوى (صدق المحكمين) وصدق المقارنة الطرفية، وامتياز المقياس بمعاملات ثبات جيدة بطريقتي ألفا كرونباخ وإعادة التطبيق، ومن ثم؛ اشتقت المئينيات معايير للدرجات الخام.

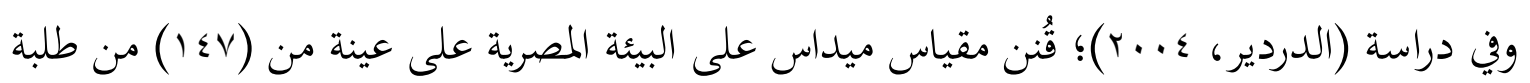
المرحلة الجامعية، وحُسب ثبات القائمة بطريقة إعادة الاختبار على عينة الدراسة الاستطلاعية من (•v) مشارگًا، وحصل الذكاء اللغوي على أعلى معامل ثبات بقيمة (rو, ·)، وأقل معامل ثبات للذكاء الموسيقي بقيمة (זی, •)، كما حُسب ثبات القائمة باستخدام الاتساق الداخلي، وتراوحت معاملات ثبات ألفا

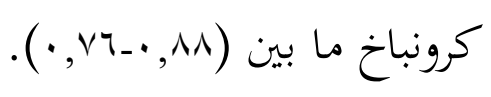

\section{ثانيًا: دراسات استخدمت مقياس ميداس للكشف عن الذكاءات المتعددة}

أجرى (Chee، r r. r. دراسة هدفت إلى تعرُّف كفاءة الإستراتيجيات المستخدمة لإشراك الطلبة في برنامج

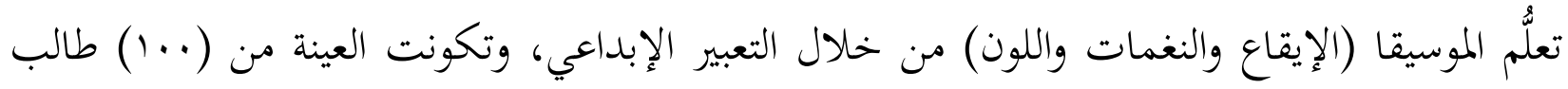
وطالبة في المرحلة الثانوية، وطُبق مقياس ميداس للمراهقين، فأشارت النتائج إلى أن الطلبة الذين حصلوا على درجات مرتفعة في مقياس ميداس كانت درجاهم مرتفعة في مختلف بجالات الموسيقا، ومن ثخ؛ بيَّنت النتائج كفاءة الإستراتيجيات المستخدمة في تنمية الذكاءات لدى الطلبة. واستُخدم في دراسة (ربابعة، م.r) مقياس ميداس لتعرُّف الفروق في الذكاءين الجسمي الحركي والمكاني بين المتفوقين رياضيَّا وغيرهم، وتكونت عينة الدراسة من (...r) طالب وطالبة من طلبة كليات التربية الرياضية في جامعة مؤتة والجامعة الأردنية، وأشارت النتائج إلى امتياز المقياس بخصائص سيكومترية جيدة، فقد استخدم الباحث الصدق الظاهري للتحقق من صدق المقياس، وبيَّنت النتائج ارتفاع معامل

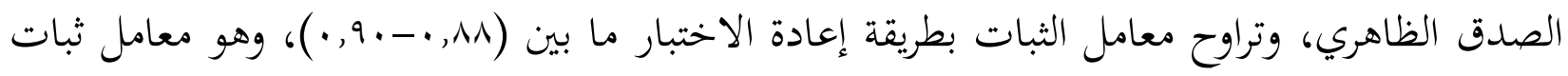

مرتفع

وهدفت دراسة (قوشحة، r...r) إلى المقارنة بين الذكاءات المتعددة لدى طلبة التخصصات العلمية والأدبية، وتناولت الدراسة تأثير السنة الدراسية (الأولى والرابعة) والنوع (الذكور والإناث)، واستخدمت مقياس ميداس (MIDAS، 1997) من تعريب الباحثة وتقنينها، وكان العدد الإجمالي للعينة (..7) طالب رلب وطالبة، واستُخدمت طريقة الثبات الداخلي للتحقق من ثبات المقياس، وتراوحت معاملات ثبات ألفا 
كرونباخ لأبعاد المقياس ما بين (^,••-^, ·)، وكذا استُخدم الصدق التمييزي لفقرات المقياس للتحقق من الصدق، وقد أشارت النتائج إلى ارتفاع صدق المفردات. واستخدمت دراسة (Ksicinski، r. r. مقياس ميداس للكشف عن الذكاءات الأكثر شيوعًا لدى الطلبة، وتكونت عينة الدراسة من (1) من طلبة كلية التمريض، وأشارت النتائج إلى أن الذكاء الاجتماعي أكثر الذكاءات شيوعًا لدى أفراد العينة، بينما كان الذكاء الموسيقي أقلها شيوعًا، وأظهرت النتائج أيضًا فروقًا دالة إحصائيَّا في الذكاء اللغوي لصالح الإناث، وفروقًا دالة إحصائيَّا في الذكاء الجسمي سئي الحركي لصالح الذكور. وفي دراسة (اللحياني، ؟ ... استُخدم مقياس ميداس لتعرُّف الفروق بين طالبات الأقسام العلمية والأدبية في الذكاءين الاجتماعي والذاتي، والكشف عن أكثر أنواع الذكاء ارتباطًا هذذين الذكاءين ومساندة لمما، وتكونت العينة من (..؟) من طالبات الفرقة الثالثة في كلية التربية للبنات في مكة المكرمة، و(... منهن طالبات في الأقسام العلمية للكلية و(·.r) منهن طالبات في الأقسام الأدبية للكلية، وأشارت النتائج إلى امتياز مقياس ميداس بخصائص سيكومترية جيدة؛ إذ استخدمت الباحثة الصدقين الظاهري والتمييزي، وحسبت التحليل العاملي للمقياس.

\section{منهج البحث وعينته}

اختير المنهج الوصفي؛ لملاءمته أهداف البحث، وتكون المجتمع الكلي للبحث من (9101) من طلبة الصف الحادي عشر يتوزعون على (vV) مدرسة في ست ولايات في محافظة شمالي الباطنة؛ هي: شناص، ولوى، وصحار، وصحم، والخابورة، والسويق، وبلغ عدد الذكور (0. بـ) بنسبة (ז, .0\%) من المجتمع الكلي، وبلغ

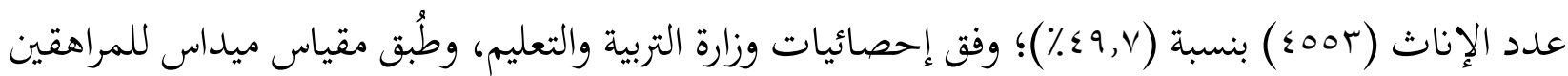

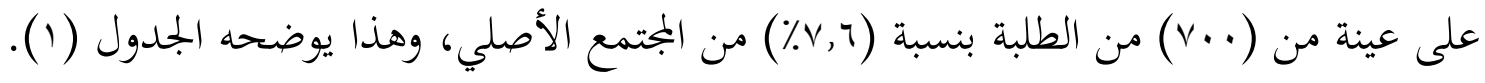




\begin{tabular}{|c|c|c|c|c|c|c|c|}
\hline & & العينة & & & الججتمع & & النوع \\
\hline عدد التلاميذ & & عدد المدارس & & عدد التلاميذ & عدد المدارس & & \\
\hline & TrI & & 7 & $\leqslant 7.0$ & & $r 7$ & ذكور \\
\hline & rvq & & 7 & soor & & YI & إناث \\
\hline & $\vee \ldots$ & & ir & 9101 & & $\varepsilon V$ & الجمموع \\
\hline
\end{tabular}

واختيرت العينة عشوائية عنقودية، بواقع مدرستين من كل ولاية؛ مدرسة ذكور، ومدرسة إناث، ومن كل مدرسة شعبتان؛ شعبة تدرس المواد (الرياضيات البحتة، الفيزياء، الكيمياء، علم الأحياء)، وشعبة تدرس المواد (الرياضيات التطبيقية، الجغرافيا، التاريخ، علم الأحياء)، وذلك لأن اختيارات معظم الطلبة تدور في هذه

المواد كما يوضح الجدول (r).

الجدول (r): عينة البحث موزعة وفق الولايات والنوع وأسماء المدارس وأعداد الفصول والطلبة

\begin{tabular}{|c|c|c|c|c|c|c|}
\hline عدد الطلبة & عدد الفصول & 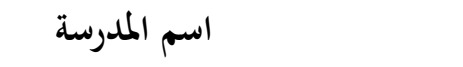 & 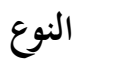 & 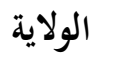 & م. & \\
\hline$\varepsilon r$ & r & سعد بن معاذ للتعليم العام & 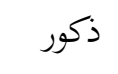 & \multirow{2}{*}{\multicolumn{2}{|c|}{ 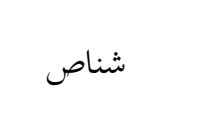 }} & 1 \\
\hline 7 & r & شناص للبنات & إناث & & & \\
\hline$\leqslant 9$ & r & الإمام الربيع بن حبيب للتعليم العام & 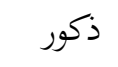 & \multirow{2}{*}{\multicolumn{2}{|c|}{ 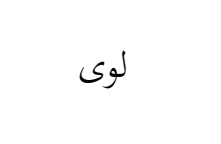 }} & \\
\hline 79 & r & المؤمنة للتعليم الأساسي & إناث & & & 1 \\
\hline $0 \wedge$ & r & صحار للتعليم الأساسي & 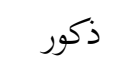 & \multirow{2}{*}{ 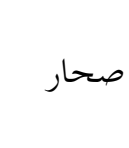 } & & \\
\hline Tr & r & أم سلمة للتعليم الأساسي & إناث & & & 1 \\
\hline ov & r & يعرب بن بلعرب & 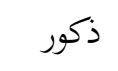 & \multirow{2}{*}{ صحم } & & \\
\hline 77 & r & عاتكة للتعليم العام & إناث & & & \\
\hline זיד & r & الفاروق للتعليم العام & ذ ذكور & \multirow{2}{*}{ 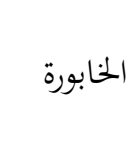 } & & \\
\hline 7. & r & صفية بنت عبد المطلب للتعليم العام & إناث & & & \\
\hline 01 & r & الوارث بن كعب & ذ ذكور & \multirow{2}{*}{ السويق } & & \\
\hline 00 & r & حليمة السعدية للتعليم العام & إناث & & & \\
\hline$v_{\cdots}$ & $r \varepsilon$ & ا ب ا مدرسة & & \multicolumn{2}{|c|}{ المجموع } & \\
\hline
\end{tabular}




\section{أداوت البحث وإجراءاته}

$$
\text { أولاً: مقياس ميداس البحث ثلاث أدوات؛ هي: }
$$

وصف المقياس: اعتمد هذا البحث مقياس ميداس للمراهقين من إعداد( Shearer، 997 ([ب])، وهو استبانة يسيرة للأفراد أعمارهم ما بين (عا-1/) عاما، وفيه ثمانية مقاييس فرعية هي: الموسيقي، والجسمي كيمي الحركي، والمنطقي الرياضي، والمكاني، واللفظي اللغوي، والاجتماعي، والذاتي، والطبيعي، ويتكون من (119)

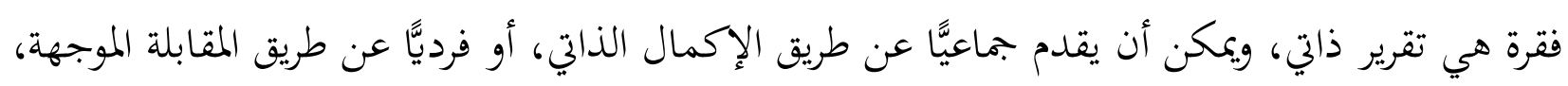
وتستغرق الإجابة عنه (•؛ ) دقيقة، وتستخدم كل فقرة مقياسًا من ست استجابات تسمح بمدى واسع من الاستجابات، وإحداها "لا أعرف"، وذلك من أجل تخفيض الغموض، ولئلا يجبر المفحوص على التخمين أو الاستجابة عكس ما يعرف.

تصحيح المقياس: صُحح المقياس بمقياس خماسي متدرج "مقياس ليكرت"، فالدرجات العالية في هذا المقياس تدل على توفُّر الذكاء لدى المفحوص، وتدل الدرجات المنخفضة على العكس، وتعطى درجات (1-0) لاستجابات المفحوص على الترتيب لكل فقرة من فقرات المقياس، ويكون التعامل مع الاستجابة

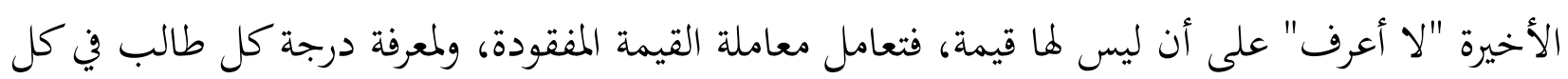
ذكاء؛ جُمعت درجاته في فقرات ذلك الذكاء، وقُسمت على عدد الفقرات التي أجاب عنها؛ أي استُبعدت الفقرات التي ذكر أنه لا يعرفها أو لا تنطبق عليه، ثم حُولت هذه الدرجات إلى درجات بتدريج جديد

$$
\text { لتكون الدرجة القصوى لكل ذكاء (·. (1) والدرجة الدنيا (•r). }
$$

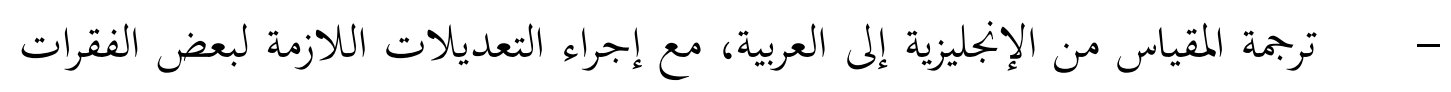

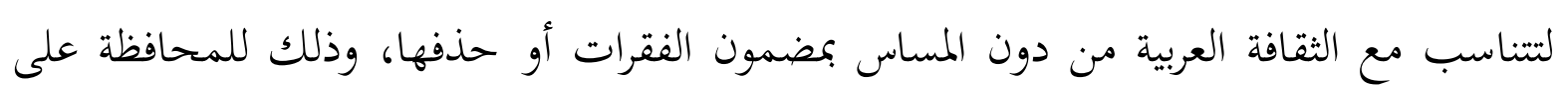
الاختبار العربي مطابقًا صيغته الأجنبية.

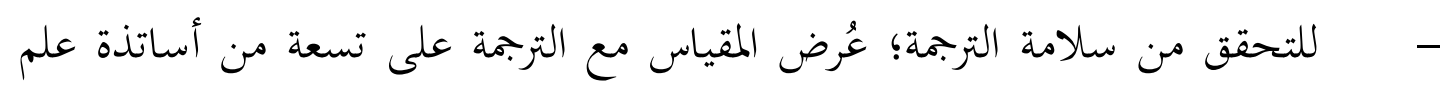

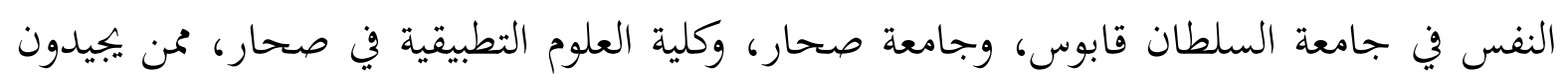


اللغتين العربية والإنجليزية، وذلك بهدف مراجعة الترجمة والتأكد من أن الصياغة العربية للفقرات تؤدي المعنى المقصود، وأسفرت ملاحظات الخبراء عن تعديل صياغة الفقرات من دون الإخلال بمحتواها.

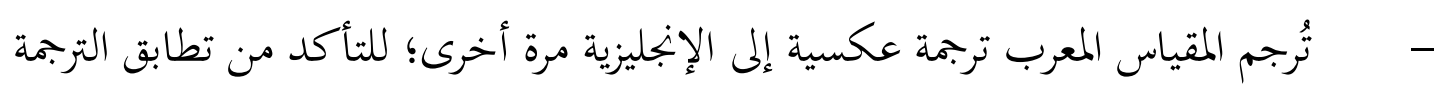
مع الأصل، وقد تحقق ذلك.

\section{ثانيًا: اختبار المصفوفات المتتابعة لرافن}

اختير هذا الاختبار للتحقق من الصدق التلازمي لمقياس ميداس، وقد ظهر لأول مرة عام روا1 باسم

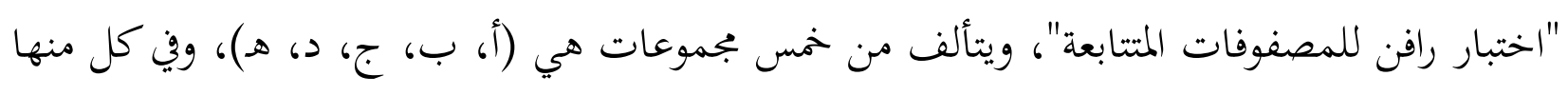
(r) فقرة؛ أي إن المجموع الكلي لفقرات الاختبار (.r) فقرة. وقد قُنن الاختبار في عدد من الأقطار العربية (العراق، السعودية، الكويت، مصر، السودان، ليبيا)، وفي

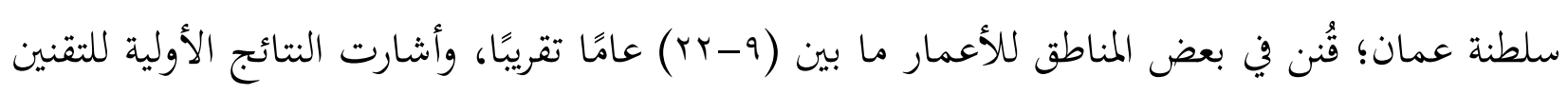
إلى ارتفاع معدلات الثبات بطريقة ألفاكرونباخ؛ إذ بلغت قيمته (90, ·)، في حين تراوحت معاملات

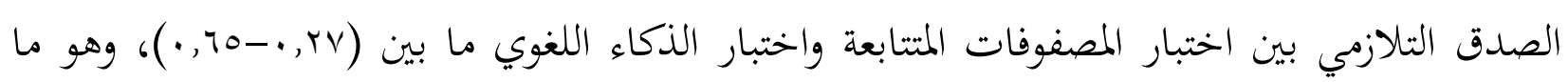
يدل على أنه يمتاز بدلالات مقبولة من الصدق والثبات (يجيى وإبراهيم وجلال، ب...ب). ثالثًا: اختبار الذكاء اللغوي

اختير هذا الاختبار للتحقق من الصدق التلازمي لمقياس ميداس، ويقيس اختبار الذكاء اللغوي القدرة العقلية العامة، ويتألف من ( • ه) فقرة تتناول إدراك العلاقات بين الكلمات وسلاسل الأعداد والاستدلال، مناك

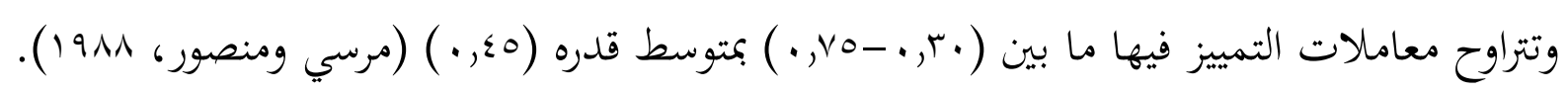

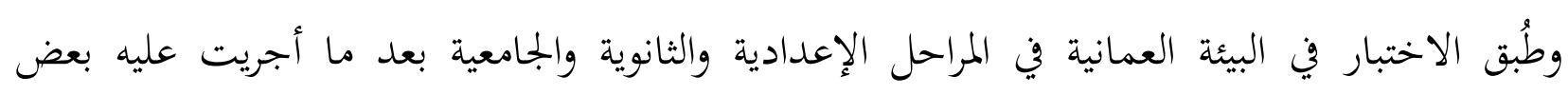
التعديلات الطفيفة، واتضح أنه يمتاز بمعاملات مقبولة من الثبات تتراوح ما بين (•0, . - . 9, . ) في المرحلة الثانوية، كما أن معاملات صدقه التلازمي مع اختبار المصفوفات المتتابعة تراوحت ما بين (Yr, •--107, •)،

$$
\text { وهي معاملات مقبولة (يجيى وإبراهيم وجلال، ب...r). }
$$

طُبق مقياس ميداس بعد الحصول على موافقة وزارة التربية والتعليم، وذلك لتسهيل عملية التطبيق على أفراد

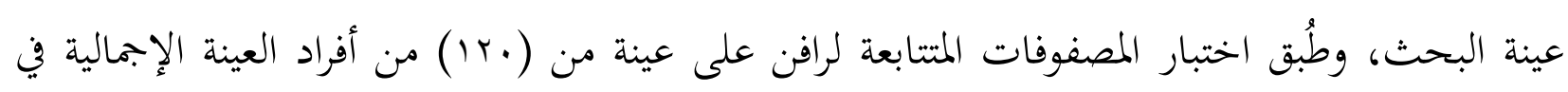
مدرستين من مدارس ولاية لوى، وذلك لحساب الصدق التلازمي مع مقياس ميداس، وطُق اختبار الذكاء 
اللغوي على عينة من (r. (1) من أفراد العينة الإجمالية في مدرستين من مدارس ولاية شناص، وذلك لحساب الصدق التلازمي مع مقياس ميداس. وفي إطار المعالجة الإحصائية اعتُمد ما يأتي:

ا ـ إدخال البيانات الخام في برنامج الحزمة الإحصائية للعلوم الاجتماعية (SPSS)؛ لتحليلها والحصول على النتائج من خلال الإجراءات الإحصائية الآتية: - - معامل ألفاكرونباخ لحساب معاملات الاتساق الداخلي.

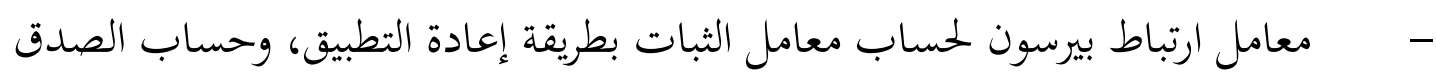
التلازمي. - - معامل ارتباط سبيرمان لحساب مدى التوافق بين الرتب وفق متغيري التخصص والنوع.

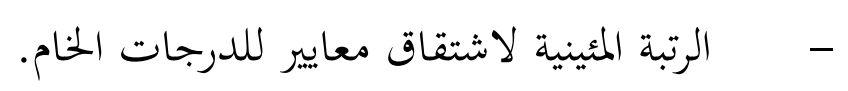

r · برنامج LISREL8.14؛ لإجراء التحليل التوكيدي، وحساب مؤشرات حسن المطابقة.

\section{نتائج البحث}

السؤال الأول: ما مؤشرات صدق مقياس الذكاءات المتعددة على طلبة الصف الحادي عشر في محافظة شمالي الباطنة بسلطنة عمان؟ للإجابة عن هذا السؤال حُسبت دلالات الصدقين الظاهري والتلازمي، والتحليل العاملي التوكيدي، وفيما يأتي عرض النتائج ومناقشتها.

(أ) الصدق الظاهري: جرى التحقق من الصدق الظاهري لمقياس ميداس من خلال استطلاع آراء

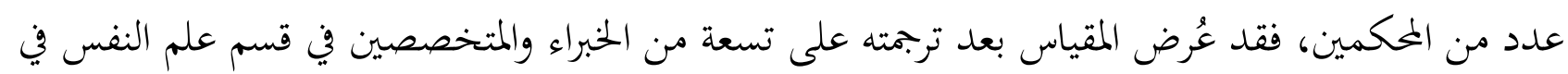
جامعة السلطان قابوس، وجامعة صحار، وكلية العلوم التطبيقية في صحار، وتبين أن فقراته صادقة ظاهريًّ؛ أي إنا تقيس ما استهدفت قياسه، وذلك من وجهة نظر غالبية المحكمين. وقد أبدى عدد من المحكمين بعض الآراء في تعديل صياغة بعض الفقرات من دون المساس بمضموها أو حذفها، وذلك للمحافظة على المقياس مطابقًا صيغته الأصلية، وكان هناك اتفاق تام على انتماء الفقرات إلى محاورها. 


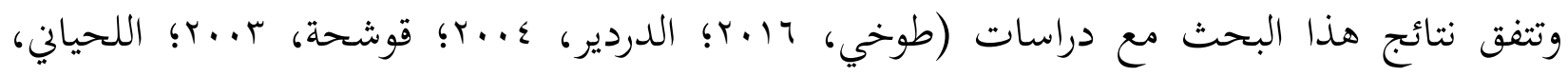

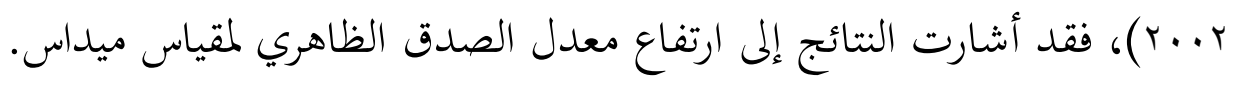
(ب) الصدق التلازمي: للتحقق من الصدق التلازمي لمقياس ميداس طُق اختبارا الذكاء اللغوي، والمصفوفات المتتابعة لرافن؛ على عينتين مختلفتين من مجتمع البحث، وحُسب معامل ارتباط بيرسون بين درجات الطلبة في مادتي اللغة العربية والرياضيات وبين أبعاد مقياس ميداس. وأظهرت النتائج أن معاملات ارتباط بيرسون بين اختبار الذكاء اللغوي وأبعاد مقياس ميداس - كما في الجدول (r) - موجبة دالة، فقد تراوحت ما بين (اץ, . -10, • )، وكان معامل الارتباط الأكبر بين اختبار الذكاء اللغوي وبُعد الذكاء اللفظي اللغوي (07, •)، محا يدل على أن هذا البُعد يقيس إلى حد كبير ما يقيسه اختبار الذكاء اللغوي، وتدل معاملات الارتباط أيضًا على أن أبعاد مقياس ميداس مجتمعة تقيس القدرة العامة، ويقيس الذكاء اللفظي اللغوي عاملاً خاصَّا. وتتفق هذه النتيجة مع نظرية سبيرمان التي ترى أن هناك عاملين؛ أحدهما عام هو القدرة العامة، والآخر

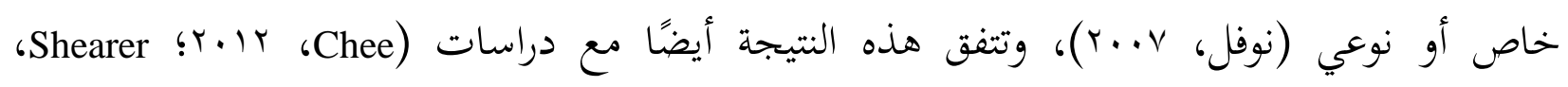
$\cdot([-]) 99 \vee$ الجدول (r): معاملات الارتباط بين اختبار الذكاء اللغوي وأبعاد مقياس ميداس (ن=r • ()

\begin{tabular}{|c|c|c|}
\hline معامل الارتباط & & أبعاد مقياس ميداس \\
\hline & $*,, Y)$ & الموسيقي \\
\hline & $*,, r \leq$ & الجسمي الحركي \\
\hline & $*_{.}, \leq 0$ & المنطقي الرياضي \\
\hline & *., Tr & المكاني \\
\hline & $*$, , 70 & اللغوي اللفظي \\
\hline & $*_{\cdot}, \varepsilon r$ & الاجتماعي \\
\hline & $*_{,}, \Sigma \Gamma$ & 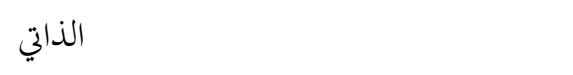 \\
\hline & $*,$, Y & الطبيعي \\
\hline
\end{tabular}


وعند تطبيق اختبار المصفوفات المتتابعة على عينة من (r.M) طالبًا وطالبة مع مقياس ميداس؛ أظهرت النتائج أن معاملات الارتباط بين المقياسين - كما يظهر الجدول (ع) - دالة موجبة، فقد تراوحت ما بين

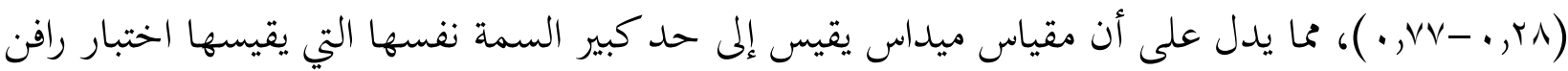
للمصفوفات المتتابعة من حيث قدرته على قياس العامل العام وفق مفهوم سبيرمان في إدراك العلاقات والمتعلقات (Anastasi، 1941)، كما أظهرت النتائج أن أكبر معامل ارتباط بين اختبار المصفوفات المتتابعة ومقياس ميداس كان مع بُعد الذكاء المكاني (VV), ·)، وتُعدُّ هذه النتيجة دليلاً قويَّ على صدق مقياس ميداس، فاختبار رافن يقيس الذكاء باستخدام الأشكال الهندسية، ويعتمد الحل على التصور المكاني لأجزاء التصميم، ويقيس القدرة المكانية (Kluever \& Green، كو91؛؛ Irvine، 1947).

الجدول (ع): معاملات الارتباط بين اختبار المصفوفات المتتابعة وأبعاد مقياس ميداس (ن=ـ ا )

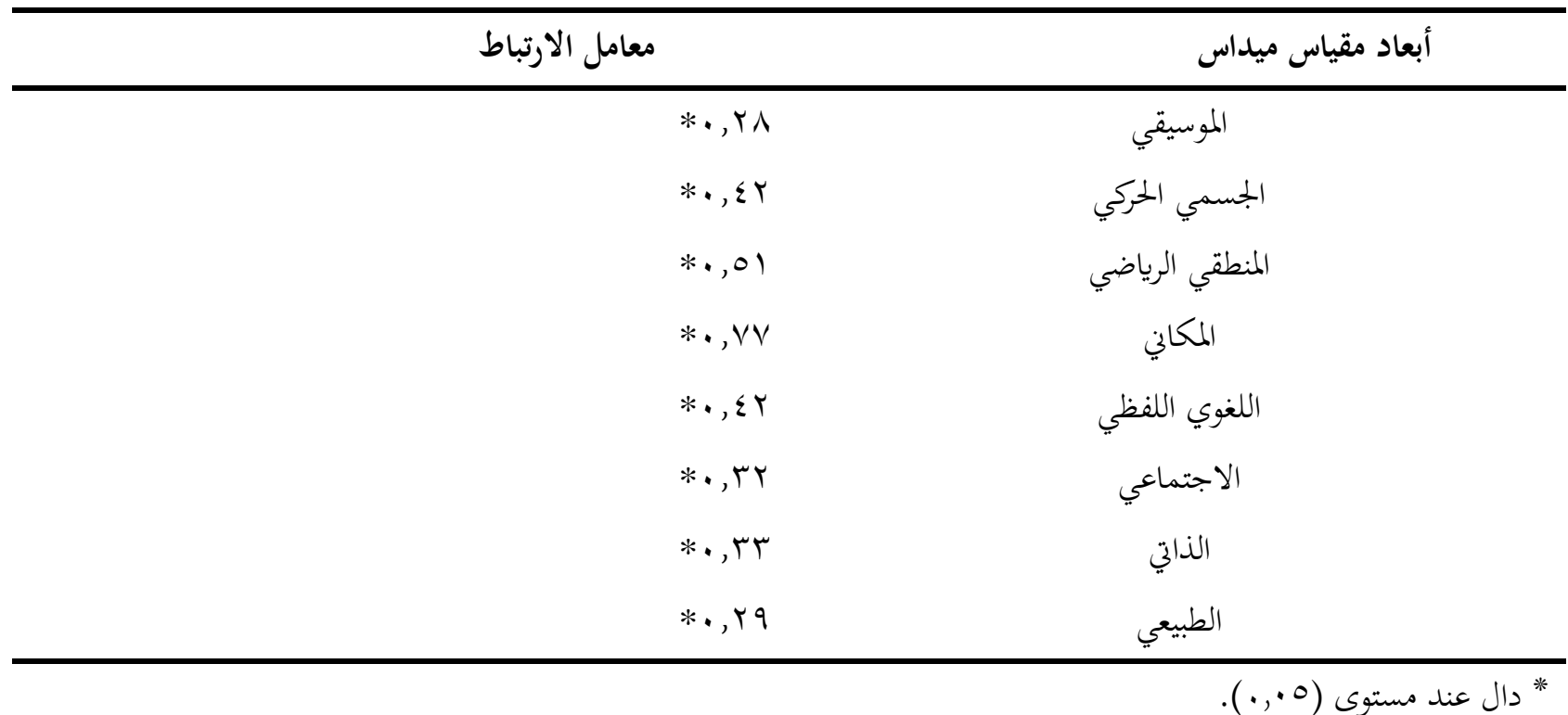

وعند حساب معاملات الارتباط بين درجات الطلبة في مادتي اللغة العربية والرياضيات وبين أبعاد مقياس ميداس على عينة من (·r) طالب وطالبة من أفراد العينة الإجمالية كما في الجدول (ه)؛ أظهرت النتائج أن هناك ارتباطات دالة موجبة بين درجات الطلبة في مادتي اللغة العربية والرياضيات مع سبعة ذكاءات هي: الجسمي الحركي، والمنطقي الرياضي، والمكاني، واللغوي اللفظي، والاجتماعي، والذاتي، والطبيعي، مما يدل على قدرة مقياس ميداس في التنبؤ بالتحصيل الدراسي للطلبة. 


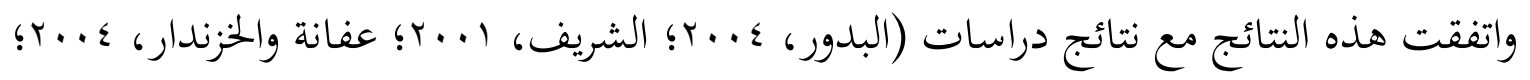

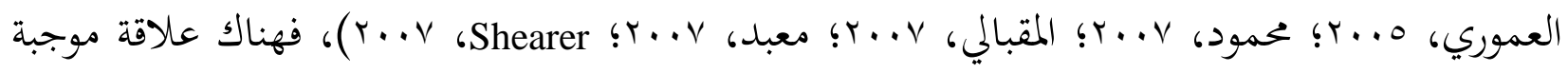
دالة بين ذكاءات الطلبة وتحصيلهم في المواد الدراسية. واختلفت هذه النتائج مع دراسة (Osborne، 1990) في أن لا علاقة دالة بين ذكاءات الطلبة وتحصيلهم في المواد الدراسية. الجدول (0): معاملات الارتباط بين درجات الطلبة في مادتي اللغة العربية والرياضيات وبين مقياس ميداس

\begin{tabular}{|c|c|c|}
\hline الرياضيات & اللغة العربية & أبعاد مقياس ميداس \\
\hline$\cdot, .7$ & $\cdot, \cdot \varepsilon$ & الموسيقي \\
\hline$* ., 1 \wedge$ & $*_{.}, 1 \wedge$ & الجسمي الحركي \\
\hline$*$, rV & $* ., Y V$ & المكاني \\
\hline *., זт & ח • • & المنطق الرياضي \\
\hline$*_{.}, \Gamma \leq$ & $*, \mu$ & اللغوي اللفظي \\
\hline *., r & $*$, , Yo & الاجتماعي \\
\hline$*_{.}, r \leq$ & $*_{.}$, r & الذاتي \\
\hline$* \cdot, r)$ & *., ro & الطبيعي \\
\hline
\end{tabular}

(ج) التحليل العاملي التوكيدي: بما أن مقياس ميداس يتبع نظرية الذكاءات المتعددة لجاردنر؛ صـيغ بعبارات تقيس كل ذكاء من الذكاءات المتعددة، واسـتُخدم التحليل العاملي التوكيدي بهدف التأكد من المكونات العاملية لمقياس ميداس للذكاءات المتعددة لمعرفة ما إذاكانت بياناته لدى الطلبة تؤكد البنية العاملية للمقياس. واستُخدمت بيانات جميع أفراد عينة البحث - ( • V) طالب وطالبة - لأداء التحليل العاملي التوكيدي باستخدام برنامج الليزرال، ويوضح الشكل (1) تشبع الفقرات على مقياس ميداس مع توضيح التباين المتبقي (المتفرد)، ويُلاحظ أن معظم التشبعات أكبر من (r, •)، وبذلك يمكن الحكم على صدق انتماء الفقرات إلى العوامل. 

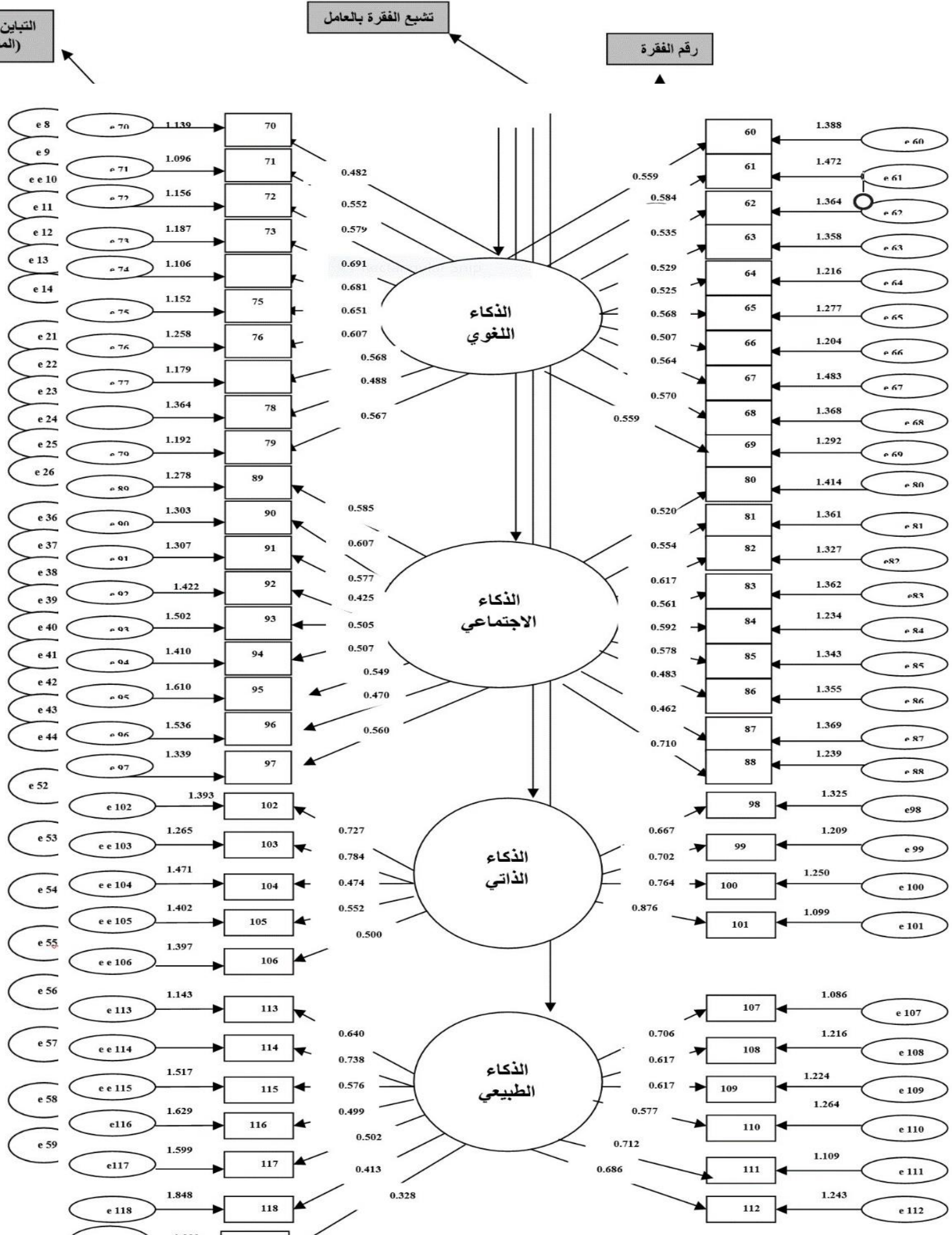

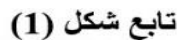

تقدير معالم النموذج العاملي التوكيدي لمقياس ميداس 
ونلاحظ من الشكل (1) ارتباطات بين الذكاءات الثمانية لمقياس ميداس، ويظهر مصفوفتها الجدول

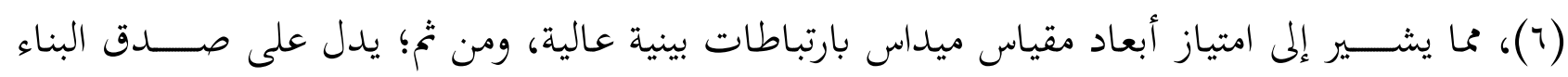
الداخلي للمقياس. الجدول (ج): مصفوفة قيم معاملات الارتباط بين الذكاءات الثمانية لمقياس ميداس

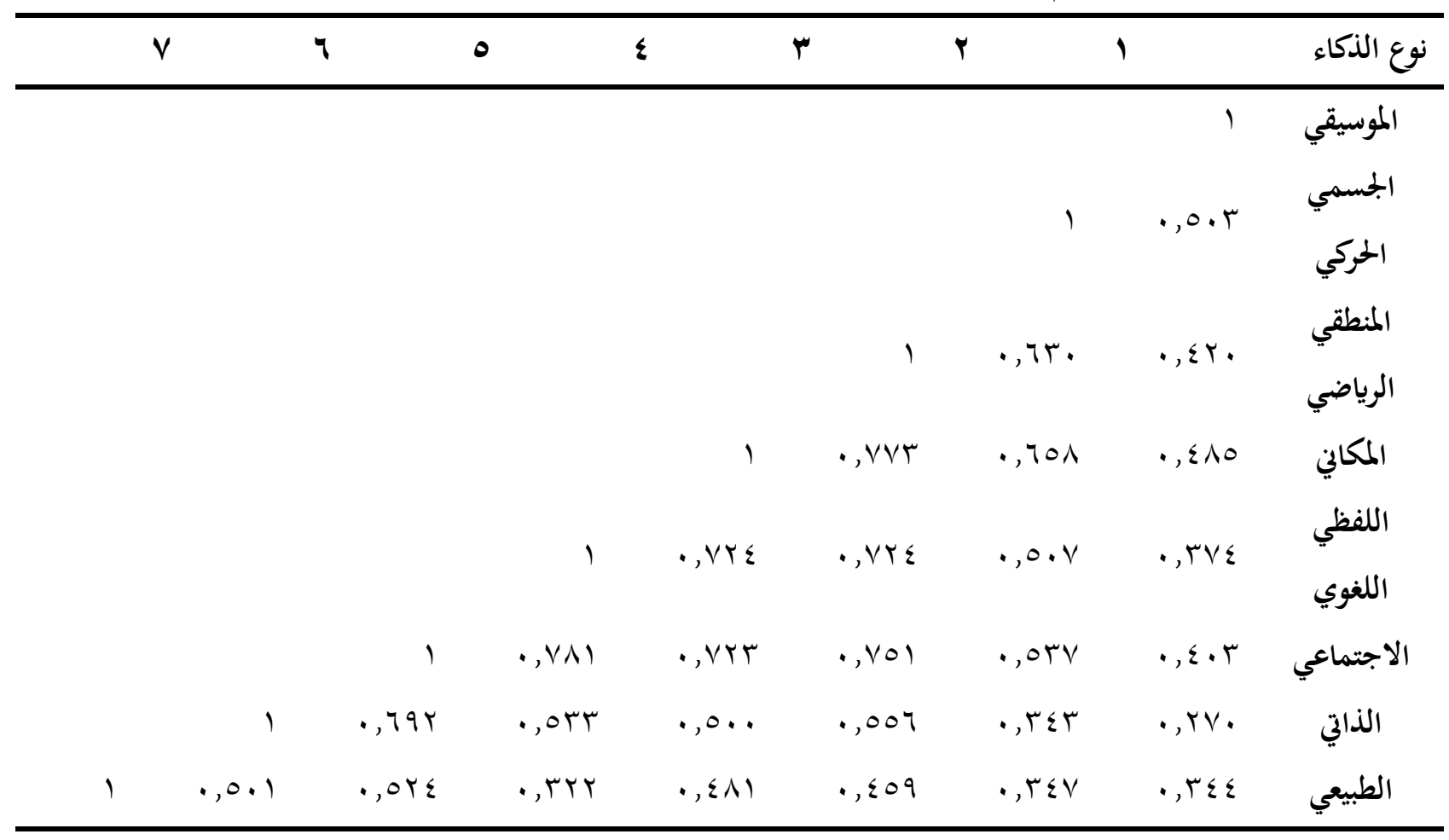

ويعرض الجدول (vو) مؤشرات حسن المطابقة لبنية مقياس ميداس متمثلة في ثمانية ذكاءات مستقلة، وتظهر النتائج أن أغلب مؤشرات المطابقة لمقياس ميداس تقترب من المدى المثالي:

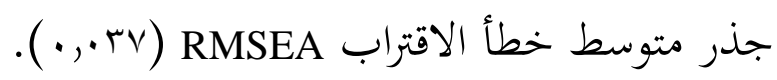
مؤشر المطابقة غير المعياري NNFI ( بrو,. ).

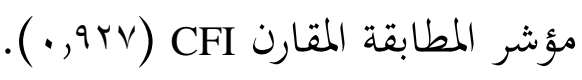
مؤشر المطابقة المتزايد IFI (

ويؤكد التحليل العاملي التوكيدي بعامـة أن المكونات العاملية لمقياس ميداس تتكون من ثمانية

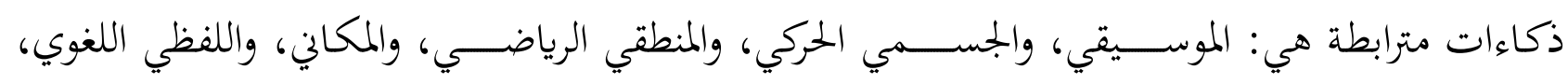


والاجتماعي، والذاتي، والطبيعي، كما أشـارت قيم تشبعات فقرات مقياس ميداس مع المكونات الثمانية إلى

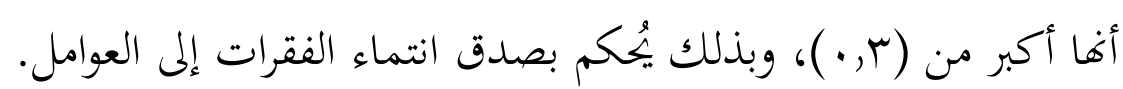
الجدول (V): مؤشرات حسن المطابقة لمقياس ميداس للذكاءات المتعددة

\begin{tabular}{|c|c|c|c|}
\hline المدى المثالي للمؤشر & 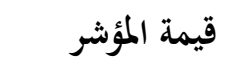 & اسم المؤشر & م. \\
\hline كا' غير دالة إحصائيًا & $* 1, Y V 1,901$ & الإختبار الإحصائي كا' 22 & 1 \\
\hline$\cdot, 9 \cdot<$ & $\cdot, 7 \wedge \varepsilon$ & مؤشر حسن المطابقة GFI & r \\
\hline$\cdot, 9 \cdot<$ & $\cdot, T V Y$ & مؤشر حسن المطابقة المصحح AGFI & $r$ \\
\hline$\cdot, .0>$ & $\cdot, \cdot r V V$ & جذر متوسط خطأ الاقتراب RMSEA & $\varepsilon$ \\
\hline$\cdot, 9 \cdot<$ & $\cdot, \wedge \cdot 9$ & مؤشر المطابقة المعياري NFI & ○ \\
\hline$\cdot, 9 \cdot<$ & $\cdot, 9 r 7$ & مؤشر المطابقة غير المعياري NNFI & 7 \\
\hline$\cdot, 9 \cdot<$ & $\cdot, 9 r V$ & مؤشر المطابقة المقارن CFI & v \\
\hline$\cdot, 9 \cdot<$ & $\cdot, 9 r v$ & مؤشر المطابقة المتزايد IFI & $\wedge$ \\
\hline
\end{tabular}

السـؤال الثاني: ما مؤشـرات ثبات مقياس الذكاءات المتعددة على طلبة الصـف الحادي عشـر في محافظة شمالي الباطنة بسلطنة عمان؟

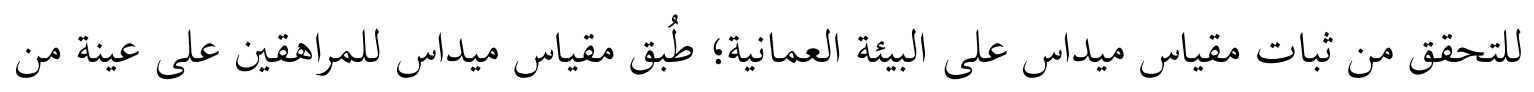
(...) طالبٍ وطالبة من طلبة الصف الحادي عشر موزعين على مدرستين من مدارس منطقة شمالي الباطنة؛

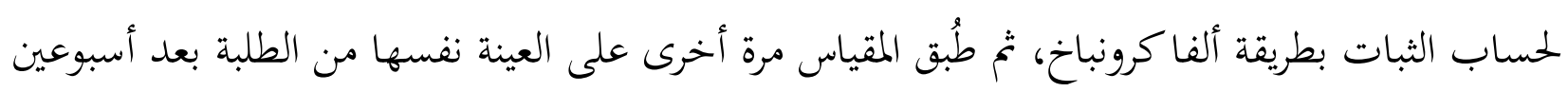
من التطبيق الأول؛ لحساب الثبات بطريقة إعادة التطبيق. 
الجدول (^): معاملات ثبات المقياس بطريتتي الاتساق الداخلي والتطبيق وإعادة التطبيق (ن=. ․ 1)

\begin{tabular}{|c|c|c|c|}
\hline معامل الثبات بإعادة التطبيق & معامل ألفا كرونباخ & عدد الفقرات & 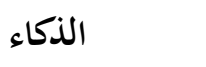 \\
\hline$\cdot, \lambda r$ & $\cdot, \wedge \leq$ & $1 \varepsilon$ & الموسيقي \\
\hline$\cdot, V \varepsilon$ & $\cdot, 7 \wedge$ & ir & الجسمي الحركي \\
\hline$\cdot, \vee \vee q$ & • & iv & لمنطقي الرياضي \\
\hline$\cdot, \wedge$ & $\cdot, \wedge \vee$ & 10 & المكاني \\
\hline$\cdot, V_{T}$ & $\cdot, \wedge \wedge$ & $r$. & اللغوي اللفظي \\
\hline$\cdot, V r$ & •, & 11 & الاجتماعي \\
\hline דוד, & $\cdot, \vee \wedge$ & 9 & الذاتي \\
\hline$\cdot$, vo & $\cdot, \wedge \wedge$ & r & الطبيعي \\
\hline
\end{tabular}

ويوضح الجدول (^) قيم معاملات الثبات للذكاءات الثمانية، وقد تراوحت معاملات ثبات ألفا

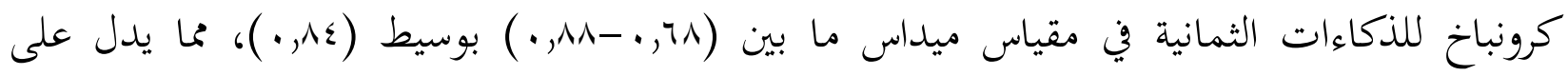
معاملات ثبات مرتفعة نسبيًّ، بينما تراوحت معاملات الثبات للذكاءات الثمانية في مقياس ميداس بطريقة

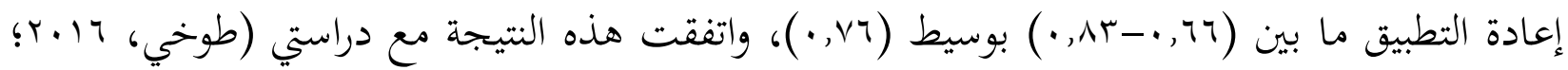

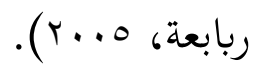

السؤال الثالث: ما المعايير لدرجات مقياس الذكاءات المتعددة على طلبة الصف الحادي عشر

في محافظة شمالي الباطنة بسلطنة عمان؟

للوصول إلى معايير تساعد في تفسير أداء الطلبة في مقياس ميداس اشُتقت الرتب المئينية Percentile Ranks معايير للدرجات الخام باستخدام عينة البحث، واستُخدم الرتبة المئينية معايير نظرًا إلى شيوع استخدامها وسهولة فهمها بين المعلمين ومستخدمي المقاييس النفسية والتربوية؛ إذ تُقدم الرتبة المئينية صورة واضحة عن مركز الفرد النسبي في مجموعة التقنين التي ينتمي إليها؛ بتحديد نسبة الأفراد الذين يقلون في مستواهم عن مستوى الفرد في السمة المقاسة (199> Anastasi \& Urbina، (19). وقد حُسـبت ثماني رتب مئينية للدرجات الخام لكل ذكاء من الذكاءات المتعددة في مقياس ميداس، ليمكن تحويل الدرجة الخام التي يمصـل عليها الطالب في الذكاء الواحد إلى رتبة مئينية تمثل مسـتوى الذكاء لديه مقارنة بزملائه في المستوى نفسه، وتتوفر جداول الرتب المئيية لمقياس ميداس في التقرير الفني للمقياس. 


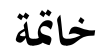

من خلال عرض نتائج هذا البحث ومناقشتها يمكن تقديم التوصيات الآتية: ا ـ اســتخدام مقياس ميداس في التوجيه المهني؛ إذ ترتبط الاهتمامات المهنية ارتباطًا قويَّ بذكاءات الطالب. r. الاســفادة من معايير البحث في تعرُّف مسـتوى الذكاءات المتعددة لدى كل طالب، ومن ثم توجيهه مهنيَّا.

r. تطوير المنهاج التعليمي لتكون فيه نشاطات تُنمي مختلف أنواع الذكاءات لدى الطلبة. ع. استخدام المعلمين مقياس ميداس؛ للكشف عن ذكاءات الطلبة، والعمل على تنميتها باستخدام

$$
\text { أساليب التدريس المناسبة. }
$$

1. التوسع في تقنين مقياس ميداس على محافظات أخرى في سلطنة عمان. Y. إجراء دراسات مماثلة على عينات مختلفة لم تُدرس من قبل؛ من من مثل: مئل

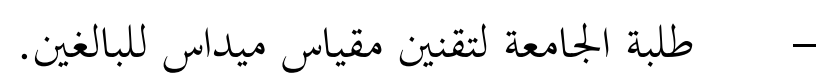
- - ملبة التعليم الأساسي لتقنين مقياس ميداس للأطفال. r. إجراء دراسة تستهدف الكشف عن العلاقة بين ذكاءات الوالدين وأولادهم. ع ـ إجراء دراسة تستهدف الكشف عن العلاقة بين مقياس ميداس ومقاييس الميول المهنية.

\section{المراجع}

الأنصاري، بدر محمد (r..r). المرجع في مقاييس الشخصية. الكويت: دار الكتاب الحديث.

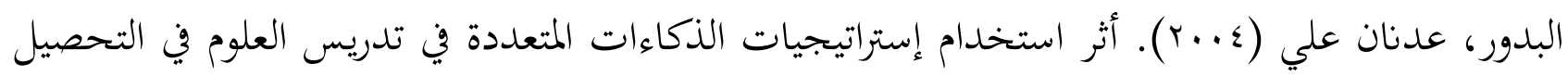
واكتساب عمليات العلم لدى طلبة الصف السابع الأساسي. رسالة دكتوراة غير منشورة، جامعة إنساء عمان العربية للدراسات العليا، الأردن. 
جاردنر، هوارد (199V). رعاية التباين في الذكاء بتقديم التعليم المناسب لكل شخص: ما يترتب على تصور

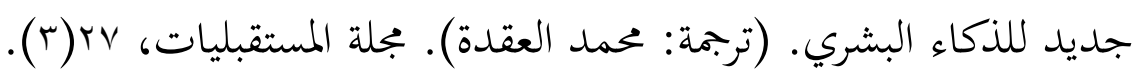

الخزندار، نائلة نجيب (r.r.r). واقع الذكاءات المتعددة لدى طلبة الصف العاشر الأساسي بغزة وعلاقته بالتحصيل في الرياضيات وميول الطلبة نحوها وسبل تنميتها. رسالة دكتوراة غير منشورة، جامعة عين شمس، مصر.

الدردير، عبد المنعم (ع ..ب). دراسات معاصرة في علم النفس المعريف. القاهرة: عالم الكتب. رافن، جون (19V7) ). اختبار المصفوفات المتتابعة. (ترجمة: فهمي، مصطفى؛ زهران، حامد؛ أبو حطب، فؤاد؛ خضر، علي؛ محمود، يوسف). مكة المكرمة: مركز البحوث النفسية والتربوية.

ربابعة، أحمد عبد الله (ب.r). دراسة مقارنة للذكاء الجسمي الحركي والذكاء المكاني البصري وفق نظرية الذكاءات المتعددة بين المتفوقين وغير المتفوقين رياضيَّا من طلبة كليات التربية الرياضية في الأردن. رسالة ماجستير غير منشورة، جامعة عمان العربية للدراسات العليا، الأردن.

الشريف، صلاح الدين حسين (1.....). التنبؤ بالتحصيل الدراسي في ضوء نظريتي معالجة المعلومات والذكاءات المتعددة. مجلة كلية التربية، جامعة أسيوط، (1). (1). طوخي، ليلى (17. (ب). تقنين مقياس الذكاءات المتعددة MIDAS- TEEN لدى طالبات المرحلة المتوسطة

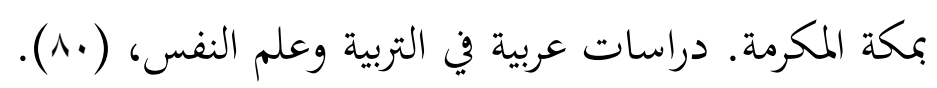
عفانة، عزو إسماعيل؛ الخزاندار، نائلة نجيب (ع +ب). مستويات الذكاء المتعددة لدى طلبة مرحلة التعليم

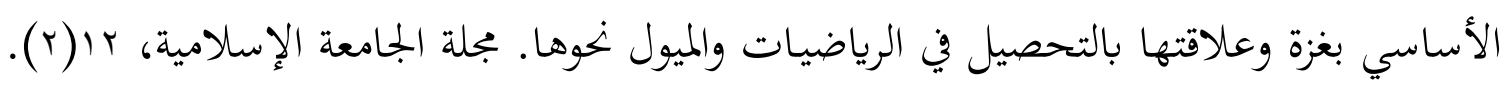
علام، صلاح الدين (؟ .. r). القياس والتقويم التربوي والنفسي أساسياته وتطبيقاته وتوجهاته المعاصرة. القاهرة: دار الفكر العربي. 


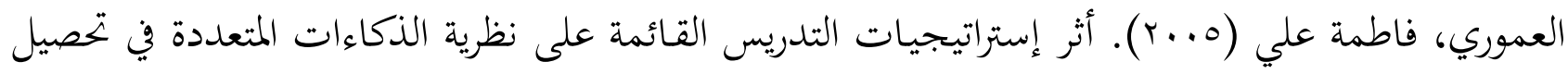
الطالبات وابتاهاتهن نحو الكيمياء. رسالة ماجستير غير منشورة، جامعة السلطان قابوس، سلطنة

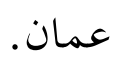
قوشحة، رنا عبد الرحمن (r . .r). دراسة الفروق في الذكاء المتعدد بين طلاب بعض الكليات النظرية والعلمية. رسالة دكتوراة غير منشورة، معهد البحوث التربوية، جامعة القاهرة، مصر.

اللحياني، مريم (r..r). فاعلية الذات الاجتماعية وعلاقتها بالذكاء الشخصي (الاجتماعي الذاتي) وفق نموذج جاردنر للذكاء المركب لدى عينة من طالبات الأقسام العلمية والأدبية بكلية التربية للبنات بمكة المكرمة. رسالة ماجستير غير منشورة، جامعة أم القرى، المملكة العربية السعودية.

محمود، عبد الرزاق مختار (r.PV). فعالية برنامج تدريبي مقترح في إكساب معلمي اللغة العربية مهارات

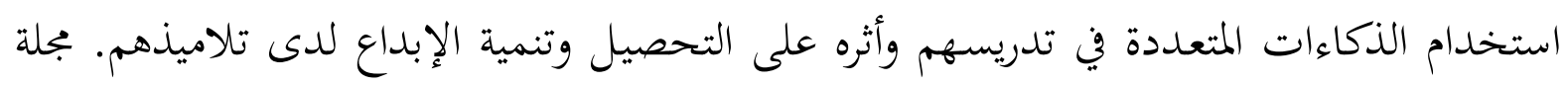

$$
\text { كلية التربية، جامعة أسيوط، (rr). }
$$

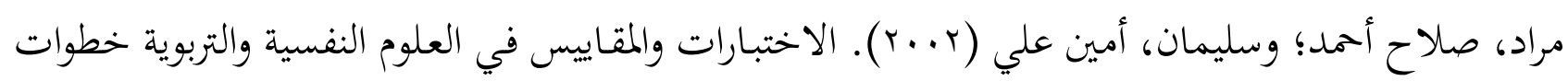
إعدادها وخصائصها. القاهرة: دار الكتاب الحديث.

مرسي، كمال؛ منصور، عبد المجيد (911). اختبار الذكاء اللغوي: دليل الاختبار ومعاييره على البيئة السعودية. الكويت: دار القلم.

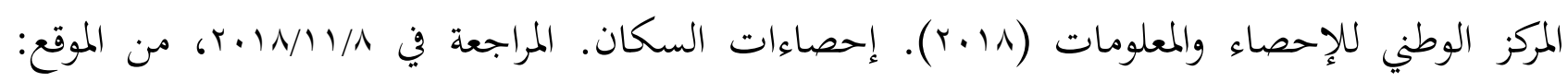
https://www.ncsi.gov.om/Elibrary/Pages/LibraryContentDetails.aspx?ItemID=bphu4H9UiUt AoGJngeETYw\%3d\%3d

معبد، علي كمال (Y.... (Y). أثر برنامج مقترح في التاريخ قائم على أنشطة الذكاءات المتعددة على تنمية التحصيل وبعض مهارات التفكير التاريخي لدى طلاب الصف الأول الثانوي. مجلة كلية التربية،

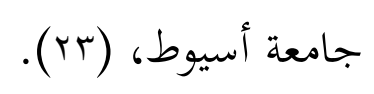




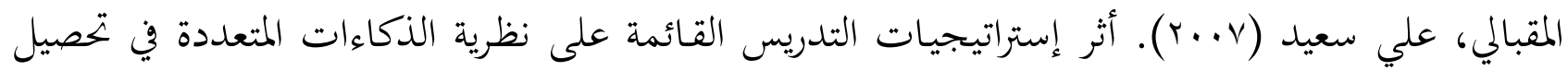

$$
\begin{aligned}
& \text { الطلبة وتفكيرهم الرياضي. رسالة ماجستير غير منشورة. جامعة السلطان قابوس، سلطنة عمان. } \\
& \text { نوفل، محمد بكر (r...r). الذكاء المتعدد في غرفة الصف النظرية والتطبيق. عمّان: دار المسيرة. } \\
& \text { وزارة التربية والتعليم (؟ . +ץ). وثيقة التوجيه المهني. مسقط، المديرية العامة للتوجيه المهني. } \\
& \text { يهيى، علي؛ إبراهيم، علي؛ جلال، أحمد (r.+r). تقنين اختبار المصفوفات المتتابعة لرافن في البيئة العمانية } \\
& \text { (محافظة مسقط). سلسلة الدراسات النفسية والتربوية، جامعة السلطان قابوس. }
\end{aligned}
$$

Anastasi, A. \& Urbina, S. (1997). Psychological Testing. (7th ed.). NJ: Prentice-Hall, Inc.

Chee, T. (2012). Engaging Students In Learning and Creating Music Through Multi Modal Strategies And Approaches: Using The Theory of Multiple Intelligences. Clute Institute International Conference - March 2012 Bangkok, Thailand.

Gardner, H. (1983). Frames of mind: The theory of multiple intelligences.New York: Bacic Books.

Gardner, H. (1993). Multiple intelligences: The theory in practice. New York: Basic Books.

Gardner, H. (1999). Intelligence reframed: Multiple intelligences for 21st century. New York: Basic Books.

Helms, J. (1992). Why is there no study of cultural equivalence standardized cogitative ability testing? American Psychologist, 47(9), 1083 - 1101.

Irvine, S. H. (1966). Towards a rationale for testing attainments and in Africa, Brit. Journal of Educational Psychology, 39, 19, 24-32.

Kluever, R. C. \& Green, K. E. (1993). An examination of ethnic and gender differences in the Ravens Colored Progressive Matrices Test. Paper presented at the annual meeting of the American Educational Research Association, (New Orleans, LA, April 4-8, 1994).

Ksicinski, J (2002). Assessment of a remedial community college cohort for multiple intelligences. Unpublished Doctoral Dissertation: University of South Dakota.

Osborne, F. (1995). Evaluation of an instrument for measuring multiple intelligences. Revised version of a paper presented at the Annual Meeting of the Kentucky academy of scienses (Ashland, Ky, October 1992). ERIC, ED: 382634.

Shearer, B. (1996A). The MIDAS: Aprofessional manual. Columbus, Ohio: Greydon Press.

Shearer, B. (1996B). Multiple the intelligence. Developmental assessment scale. Columbus, Ohio: Greydon Press. 
Shearer, B. (1997a). Development and validation of multiple intelligences assessment scale for children. Paper presented at the annual meeting of the American psychological association (105th, Chicago, IL, August 15-19) ERIC, ED: 415475.

Shearer, B. (1997b). Reliability, validity and utility of multiple intelligences assessment for career planning.Paper presented at the Annual Meeting of the American Psychological Association (105th, Chicago, IL, August 15-19, 1997). ERIC, ED: 415476.

Shearer, B. (2002). Using a multiple intelligences assessment to facilitate teacher development. EDRS, ED: 463323. 